\title{
CIÊNCIA E TECNOLOGIA: TRANSFORMANDO O HOMEM E SUA RELAÇÃO COM O MUNDO
}

\section{SCIENCE AND TECHNOLOGY: TRANSFORMING THE HUMAN BEING RELATION WITH THE WORLD}

\author{
Rosemari Monteiro Castilho Foggiatto Silveira ${ }^{1}$; Walter Antonio Bazzo ${ }^{2}$ \\ ${ }^{1}$ Federal Technological University of Paraná - UTFPR - Ponta Grossa - Brasil \\ rosemari@pg.cefetpr.br \\ Doutoranda Universidade Federal de Santa Catarina - PPGECT* - UFSC Florianópolis - SC \\ ${ }^{2}$ Departamento de Engenharia Mecânica - PPGECT* da UFSC - Brasil wbazzo@emc.ufsc.br \\ NEPET - Núcleo de Estudos e Pesquisas em Educação Tecnológica - Florianópolis - SC \\ Programa de Pós-Graduação em Educação Científica-Tecnológica
}

\begin{abstract}
Resumo
Nesse artigo evidencia-se a transformação da relação do ser humano com o mundo causada pelo avanço científico-tecnológico. Dessa forma, o propósito do artigo é refletir como a ciência e a tecnologia vieram se instalando no mundo, quais as concepções e ideologias que estão por trás de todo o desenvolvimento científico-tecnológico. Inicialmente busca-se mostrar como tradicionalmente a ciência é vista. Na seqüência, comenta-se sobre a origem e disseminação da tecnologia, como ela sofre e causa transformações profundas de caráter político, social, econômico e filosófico na história do século XVII em diante. Por último, defende-se a pertinência de se pensar o desenvolvimento científico e tecnológico numa perspectiva social, das modificações que a ciência e a tecnologia vêm sofrendo após a Segunda Guerra Mundial e da importância do movimento CTS como impulsionador de questionamentos críticos e reflexivos acerca do contexto científicotecnológico e social.
\end{abstract}

Palavras-chave: CTS (Ciência, Tecnologia e Sociedade), Educação Tecnológica, Tecnologia e Ciência.

\section{Introdução}

Após a II Guerra Mundial a imagem da ciência e da tecnologia passou a sofrer modificações. Inicialmente o desenvolvimento tecnológico foi valorizado positivamente por ser considerado a alavanca do progresso e bem-estar-social. As políticas públicas eram basicamente políticas de promoção de maneira que no modelo linear de desenvolvimento tecnológico que se estabelecia, não havia lugar para as conseqüências negativas da mudança tecnológica.

A ciência ao longo dos anos vem ganhando importância. Embora ela exista desde os primórdios da civilização, a ciência não era essencial para qualquer finalidade técnica até o século 
XVI, quando se tornou indispensável à navegação. Entretanto, continuou não tendo muitas aplicações até o século XIX, quando então se tornou necessária, à química e à engenharia.

O avanço científico e tecnológico possibilitou a Revolução Industrial. Porém, Bernal (1969) afirma que, a maquinaria da Revolução Industrial não foi um simples presente dos inventores, ela ocorreu porque havia disponibilidade de capital e mão-de-obra. As oportunidades que o mercado oferecia para a obtenção dos lucros fizeram com que se desenvolvessem em grande velocidade. A criação de novo processo, nova máquina, ou novo princípio científico, como por exemplo, a produção de energia elétrica por magnetismo (Faraday) proporcionou uma modificação nas condições de produção e novas oportunidades de transformação econômica.

Carvalho (1997, p.72) comenta que, a partir da Revolução Industrial os conhecimentos tecnológicos e a estrutura social foram modificados de forma acelerada. Porém, foi a partir da segunda metade do séc. XX que a humanidade mais acumulou conhecimentos e mais acelerou o processo de transformações sociais. Com isso, surgiram novos problemas inexistentes anteriormente como, por exemplo, com as transformações na forma de propriedade da terra. Muitos camponeses destituídos dos meios de produção foram expulsos do meio rural e migraram para a cidade em busca de trabalho na indústria. Isso fez com que as cidades crescessem desordenadamente gerando problemas cruciais como: habitação, saúde, educação, saneamento, entre outros. Também, o aumento do número de trabalhadores desempregados fez baixar o valor da força de trabalho e pressionou os trabalhadores empregados a manter sob relativo controle suas reivindicações por melhores salários e melhores condições de trabalho.

Diante disso, Carvalho (1997, p.74) utilizando as palavras de Marx (1975) afirma: "uma característica que marca o capitalismo desde o início é a oposição entre pobreza de um lado e riqueza de outro, isto é, à medida que a acumulação de capital se realiza cada vez mais plenamente, cresce também a população que não tem acesso a esta riqueza".

Isso fez com que a sociedade se visse diante das incertezas com relação a valores, padrões e modelos de comportamento que hoje são considerados superados, e Geertz apud Carvalho (1997) argumenta que, a cultura (regras, padrões, planos, receitas, modelos, etc.) que regula e orienta os comportamentos dos seres humanos em sociedade, não acompanha a aceleração das mudanças tecnológicas atuais que cada vez mais cria novas necessidades aos seres humanos, tornando-se um processo irreversível, já que, apesar de grande parte da população não ter acesso aos benefícios de seu desenvolvimento, não se pode deixar de considerar que o progresso tecnológico possibilita a vida mais fácil e mais confortável.

Carvalho (1997, p.73) ainda acrescenta: "Esta é uma das razões do êxito do capitalismo que vem transformando definitivamente a vida humana sobre a face da Terra, criando novas relações sociais e culturais e associados a elas, novos atores sociais que passarão a viver contradições 
específicas de uma sociedade de classes”. A autora lembra que não foi toda a humanidade que se incorporou ao sistema capitalista. Existem povos de diferentes partes do planeta que seguiram outro caminho histórico, de forma que a sociedade mercantil capitalista, com base no desenvolvimento tecnológico, não é a única possibilidade de organização social criada pela superação, como já aconteceu no passado com outras formações sociais. Entretanto, não se possa negar que o desenvolvimento tecnológico, seja um processo irreversível para as pessoas que o vivenciam.

Esses são alguns dos aspectos que ressaltam a necessidade de se pensar o desenvolvimento científico-tecnológico numa dimensão mais social, pois a tecnologia está ligada ao trabalho do ser humano e não pode ser um simples estudo mecânico, um somatório de técnicas como nas concepções convencionais nem ser vista como principal via de avanço da humanidade.

$\mathrm{Na}$ perspectiva de mudanças desse quadro é que esse artigo tem por objetivo trazer reflexões de como a ciência e a tecnologia vieram se instalando no mundo, quais concepções e ideologias estão por trás do desenvolvimento científico-tecnológico. A finalidade é de proporcionar o debate sobre essa relação de desenvolvimento científico-tecnológico e desenvolvimento social e também de ressaltar a importância do movimento CTS como impulsionador de questionamentos críticos e reflexivos sobre o contexto científico-tecnológico e social.

\section{A Visão Tradicional da Ciência}

A ciência tem recebido várias definições, mas uma das mais aceita pela comunidade científica é a proposta pela UNESCO que declara: "a ciência é o conjunto de conhecimentos organizado sobre os mecanismos de causalidade dos fatos observáveis, obtidos através do estudo objetivo dos fenômenos empíricos".

Tradicionalmente, a ciência é vista como um empreendimento autônomo, objetivo e neutro baseado na aplicação de um código de racionalidade alheio a qualquer tipo de interferência externa. Segundo Bazzo, Linsingen e Pereira (2003, p.14), nessa concepção o que garante a cientificidade é o "método científico", ou seja, é o procedimento regulamentado para avaliar a aceitabilidade de enunciados gerais baseados no seu apoio empírico e, adicionalmente, na sua consistência com a teoria da qual devem formar parte. Uma qualificação particular da equação "lógica + experiência" deveria proporcionar a estrutura final do "método científico".

O desenvolvimento científico é concebido como um processo regulado por um rígido código de racionalidade autônomo em relação a condicionantes externos, tais como: sociais, políticos, psicológicos, entre outros, em que, nas situações de incertezas, apela-se para algum critério metafísico objetivo, valorizando a simplicidade, o poder preditivo, da fertilidade teórica e do poder 
explicativo sendo o desenvolvimento temporal do conhecimento científico visto como avanço linear e cumulativo, como paradigma de progresso humano.

Enfim, pode-se dizer que a concepção positivista da ciência, defendida por Popper, trata a ciência como se ela fosse neutra, totalmente destituída de qualquer ação humana, de maneira que o observável independe das impressões sensíveis, das expectativas, dos preconceitos e do estado interno geral do observador. Entretanto, questiona-se: Onde ficam os valores do pesquisador, a dimensão social e a contextualização com a realidade nesse tipo de pesquisa? $\mathrm{O}$ pesquisador consegue se manter totalmente à parte do processo? A quem interessa esse tipo de pesquisa? Japiassu (1981, p143) questiona a neutralidade científica levantando a seguinte questão: “qual ciência, em suas pesquisas, deixa de fazer apelo a certos valores e a certas normas éticas?". O autor acrescenta, "ela faz apelo, pelo menos, à norma ética segundo a qual todo conhecimento deve ser objetivo" (grifo do autor).

Contrário a essa linha de pensamento, a partir de Kuhn, a filosofia toma consciência da importância da dimensão social e do enraizamento histórico da ciência, ao mesmo tempo em que inaugura um estilo interdisciplinar que tende a dissolver as fronteiras clássicas entre as especialidades acadêmicas.

Para Bazzo, Linsingen e Pereira (2003, p.21), a superação do positivismo lógico teve influência marcante de Thomas S. Kuhn ${ }^{1}$, quando em 1962, introduziu conceitos sociais para explicar como muda a ciência, sua dinâmica e seu desenvolvimento. Segundo Kuhn (1989) para se saber o que é ciência seria necessário ajustar a caracterização dos seus aspectos dinâmicos, de um estudo disciplinar da história da ciência real, o que se constituiu uma autêntica revolução na forma de abordar o problema. O autor ainda considerou que o progresso científico ocorre mediante saltos e não numa linha contínua, uma vez que a ciência tem períodos estáveis ao qual denominou de ciência normal $^{2}$ e períodos de revoluções científicas ${ }^{3}$ com aparecimento de paradigmas alternativos.

Portanto, a partir de Kuhn, é a comunidade científica que marca os critérios para julgar e decidir sobre a aceitabilidade das teorias e não a realidade empírica. Conceitos como 'busca da verdade' e 'método científico' passaram então a ser substituídos por conceitos como 'comunidade' e 'tradição'. Bazzo, Linsingen e Pereira (2003, p.22) complementam que uma das principais abordagens de Kuhn foi:

\footnotetext{
${ }^{1}$ Para melhor aprofundamento ver: Estruturas das Revoluções Científicas de Thomas S. Kuhn (1992, $3^{\mathrm{a}}$ edição).

${ }^{2}$ Para Kuhn (1989) a ciência normal é a ciência dos períodos em que o paradigma é unanimemente aceito, sem qualquer contestação pela comunidade científica se caracteriza assim porque uma comunidade científica reconhece um paradigma ou teoria, ou conjunto de teorias, que oferece soluções aos problemas teóricos e experimentais que se investigam neste momento. Bazzo, Lisingen,e Teixeira, 2003a, p. 20) acrescentam que "Durante o período de ciência normal as inovações são pouco freqüentes, já que o trabalho científico se concentra na aplicação do paradigma".

3 Kuhn (1989) também fala que as Revoluções científicas são marcadas por crises no paradigma dominante, que pelo aparecimento de paradigmas alternativos, pela disputa entre as comunidades rivais e, eventualmente, pelo possível rechaço de partes significativas da comunidade científica em relação ao paradigma antes reconhecido, ou seja os problemas do conhecimento aos quais se referia a ciência passam a ser vistos com novos olhos.
} 
de que a análise racionalista da ciência proposta pelo positivismo lógico é insuficiente, e que é necessário apelar para a dimensão social da ciência para explicar a produção, manutenção e mudança das teorias científicas. Portanto, a partir de Kuhn impõe-se a necessidade de um marco conceitual enriquecido e interdisciplinar para responder às questões traçadas tradicionalmente de um modo independente pela filosofia, pela história e pela sociologia da ciência. A obra de Kuhn dá lugar a uma tomada de consciência sobre a dimensão social e o enraizamento histórico da ciência, ao mesmo tempo em que inaugura o estilo interdisciplinar que tende a dissipar as fronteiras clássicas entre as especialidades acadêmicas, preparando o terreno para os estudos sociais da ciência.

Nesse contexto, Japiassu (1981, p.142) contribui dizendo que a fim de estabelecer um novo fundamento epistemológico para a ciência, vem sendo realizadas tentativas de reconhecer a dimensão social da prática científica e da necessidade dos cientistas tomarem consciência dessa dimensão, de forma que se desenvolva uma "epistemologia crítica", cujo objetivo fundamental seria "uma atitude reflexiva sobre os projetos de pesquisas científicas, tendo em vista a descoberta, a análise e a crítica das diferentes conseqüências funestas ao homem e a natureza gerada pela tecnologia em curso".

No âmbito dos estudos sociais da ciência, Bazzo, Linsingen e Pereira (2003) colocam que autores como B. Barnes, H. Collins e Bruno Latour passaram a usar a sociologia do conhecimento para apresentar uma visão geral da atividade científica como mais um processo social, regulado basicamente por fatores de natureza não epistêmica, os quais teriam relação com pressões econômicas, expectativas profissionais ou interesses sociais específicos.

A própria filosofia tem manifestado um crescente interesse pelo contexto. Produz-se assim uma mudança de ênfase nos detalhes das práticas científicas particulares, ressaltando a heterogeneidade das culturas científicas em contraposição ao tradicional projeto reducionista do Positivismo Lógico ${ }^{4}$.

Ravetz (1971) apud Menéndez (2004) contribui ao afirmar que a ciência tradicional, a ciência acadêmica, preocupava-se basicamente em conceber teorias verdadeiras seguindo as diretrizes marcadas, por exemplo, pelo método científico Todavia, isso começou a se modificar depois da Segunda Guerra Mundial, devido ao processo de industrialização da ciência e a criação de projetos de investigação e desenvolvimento em grande escala, como por exemplo, o Projeto Manhattan para construir a bomba atômica, os programas espaciais, a engenharia genética, a

\footnotetext{
${ }^{4}$ Positivismo Lógico: “concepção herdada da natureza da ciência e desenvolvida na Europa de entre guerras dos anos vinte e trinta do século XX por autores como R. Carnap, Neurath, H. Reichenbach ou C. Hempel. Manteve sua hegemonia filosófica até os anos sessenta e setenta. Os positivista lógicos, em geral, entendiam a ciência como 'saber metódico', ou seja, como um modo de conhecimento caracterizado por certa estrutura lógica (desvelável através da análise filosófica) e por responder a certo método, um método que combinava a avaliação empírica das hipóteses e o raciocínio dedutivo (fatores epistêmicos). Nesta concepção nega-se tradicionalmente a relevância explicativa dos fatores não-epistêmicos para o avanço em ciência". "Para os positivistas, as teorias científicas eram sobretudo conjuntos de enunciados que tratariam de explicar o mundo natural de um modo objetivo, racional e livre de qualquer valor externo à própria ciência. O conhecimento científico para quem segue essa lógica filosófica, é visto como um processo progressivo e acumulativo, articulado através de teorias cada vez mais amplas e precisas que vão subsumindo e substituindo a ciência do passado. Em alguns casos, as teorias científicas - sob a lógica do positivismo - poderiam ser aplicadas gerando desse modo tecnologias". (Bazzo, Lisingen, e Teixeira, 2003, p. 41).
} 
realidade virtual, etc. Construía-se uma nova ciência que segundo Echeverria (2001), era freqüentemente denominada tecnociência ou Big Science, a qual requeria grandes equipamentos e vultosos recursos econômicos para ser desenvolvida.

Sobre a big science, Morin (1996, p.127) fala que ela desenvolveu influentes poderes, contudo, os cientistas perderam sua autoridade, que ficaram concentrados nas mãos dos dirigentes de empresas e das autoridades do estado que financia a pesquisa científica, havendo uma extraordinária relação entre pesquisa e poder. O autor ainda acrescenta que é preciso pensar que "a big science leva a um saber anônimo que não é mais feito para obedecer à função que foi a do saber durante toda história da humanidade, a de ser incorporado nas consciências, nas mentes e nas vidas humanas".

O novo saber científico é feito para ser depositado nos bancos de dados e para ser usado com os meios e segundo as decisões das potências, ou seja, os cientistas não podem mais controlar e verificar todo saber produzido atualmente. Além disso, as pesquisas estão nas instituições tecnoburocráticas da sociedade. Por isso, a administração tecnoburocrática junto com a hiperespecialização do trabalho produz a irresponsabilidade generalizada. Dessa forma, pode-se dizer que se vive num período em que a separação dos problemas éticos e científicos pode comprometer a vida caso seja perdido de vista o caráter humano do desenvolvimento científicotecnológico.

Fazendo analogia a Kuhn, o qual afirma que no período de ciência normal o que predomina é um "paradigma científico", , Dosi apud Reis (2004, p. 70,71), propôs o conceito de "paradigma tecnológico" como, "um padrão de solução de problemas tecno-econômicos selecionado, baseado em princípios altamente selecionados derivados das ciências naturais, orientados para a aquisição de conhecimentos específicos de maneira a resguardá-los de uma rápida difusão aos competidores". Para Dosi, essa analogia se faz por que "como um paradigma científico determina o campo de questionamentos, os problemas, os procedimentos e as tarefas, também o paradigma tecnológico o determina". Esse autor ainda coloca que talvez fosse melhor falar em 'grupos de tecnologia', por exemplo, grupo de tecnologias nucleares.

Referindo-se à direção das mudanças tecnológicas ("technological change"), Dosi considera que os processos de inovação são condicionados por paradigmas cujo rumo é determinado pelo conjunto de problemas e soluções consideradas previamente relevantes e que delimitam os esforços tecnológicos. Assim, Dosi apud Reis (2004, p. 71) diz que: “Um paradigma tecnológico define contextualmente as necessidades a serem atendidas, os princípios científicos a serem usados para as tarefas e a tecnologia de materiais a ser empregada".

\footnotetext{
${ }^{5}$ Kuhn (1975) definiu o Paradigma científico àquilo que é partilhado por uma comunidade científica. O paradigma indica à comunidade o que é interessante investigar, como levar a cabo essa investigação, impondo como que um sentido ao trabalho realizado pelos investigadores e limitando os aspectos considerados relevantes da investigação científica.
} 
Também Campos (1996) contribui argumentando que os sinais de mercado podem induzir e influenciar o desenvolvimento do paradigma das estruturas competitivas nos limites tecnológicos definidos pelo paradigma corrente, e Dosi apud Reis (2004) corrobora "cada paradigma tecnológico envolve uma tecnologia da mudança técnica".

Refletindo sobre o exposto até aqui, emergem alguns questionamentos: Como vem sendo tratado a tecnologia? Qual sua origem, disseminação e sua função social? Esses são alguns dos aspectos que passaremos a discorrer na seqüência.

\title{
3. Tecnologia: sua origem e disseminação
}

Análoga à história da ciência na modernidade, a tecnologia ${ }^{6}$ sofre e causa transformações profundas de caráter político, econômico, social e filosófico, na história do séc. XVII em diante. Por isso, Miranda (2002, p.51) afirma que a tecnologia moderna não pode ser considerada um mero estudo da técnica. Ela representa mais que isso, pois nasceu quando a ciência, a partir do renascimento, aliou-se à técnica, com o fim de promover a junção entre o saber e o fazer (teoria e prática). Segundo a autora:

\begin{abstract}
A tecnologia é fruto da aliança entre ciência e técnica, a qual produziu a razão instrumental, como no dizer da Teoria Crítica da Escola de Frankfurt. Esta aliança proporcionou o agir-racional-com-respeito-a-fins, conforme assinala Habermas, a serviço do poder político e econômico da sociedade baseada no modo de produção capitalista (séc. XVIII) que tem como mola propulsora o lucro, advindo da produção e da expropriação da natureza. Então se antes a razão tinha caráter contemplativo, com o advento da modernidade, ela passou a ser instrumental. É nesse contexto que deve ser pensada a tecnologia moderna; ela não pode ser analisada fora do modo de produção, conforme observou Marx. (MIRANDA, 2002, p.51)
\end{abstract}

Nesse sentido, Bastos (1998, p.13) corrobora ao afirmar que a tecnologia é um modo de produção, o qual utiliza todos os instrumentos, invenções e artifícios e que, por isso, é também uma maneira de organizar e perpetuar as vinculações sociais no campo das forças produtivas. Dessa forma, a tecnologia é tempo, é espaço, custo e venda, pois não é apenas fabricada no recinto dos laboratórios e usinas, mas recriada pela maneira como for aplicada e, metodologicamente, organizada.

Isso evidencia que se for considerado que a tecnologia moderna está inserida e se produziu num contexto social, político e econômico determinado, originando uma sociedade capitalista, então a visão sobre a tecnologia e o seu papel na sociedade deverá ser diferente daquela que prega que a

\footnotetext{
${ }^{6}$ Bazzo, Lisingen e Teixeira (2003, p.40 e 41) esclarecem que diferentemente da técnica que faria referência a habilidades, procedimentos, artefatos desenvolvidos sem a ajuda do conhecimento científico, o termo "tecnologia" seria utilizado para se referir aos sistemas desenvolvidos levando em conta o conhecimento científico.
} 
tecnologia é um "mal necessário", pois se for compreendido que ela surgiu em certo período histórico; ela não é inerente à condição humana, ou seja, não é tão antiga quanto a técnica.

Por isso, é necessário se fazer uma avaliação crítica sobre a tecnologia, sua constituição histórica e sua função social, no sentido de não só compreender o sentido da tecnologia, mas também de repensar e redimensionar o papel da tecnologia na sociedade. Segundo Miranda (2002, p.55 e 56), é necessário dirigir a razão (o pensar) para a emancipação do homem e não para sua escravidão, como ocorre na razão instrumental, conforme a avaliação dos frankfurtianos e também conduzir a razão para emancipação, com uma maior autonomia da ciência, que nos tempos modernos tornou-se escrava da tecnologia, para redefinir qual a função social da ciência, da técnica e da tecnologia.

Passados mais de três séculos, a história do desenvolvimento tecnológico nos dá condições suficientes para avaliar as significações da tecnologia moderna que modelou a sociedade como industrial, pós-industrial e por último, da sociedade informática. Miranda (2002, p.56) cita que alguns pensadores da atualidade como: "Robert Kurz, Ramonet, Boaventura Santos, vivemos hoje o ‘colapso da modernização'. A começar pela própria confiança absoluta na ciência que emanciparia o homem de toda escravidão, obscurantismos e medo. De fato, isso não ocorreu, o que constatamos hoje é a escravidão do próprio homem pelas suas invenções e descobertas tecnológicas, só possíveis graças à aliança entre ciência e técnica". Miranda ainda acrescenta "Nunca na história da humanidade tantas pessoas morreram de fome, na miséria ou pela violência, cujos dados são apontados por Boaventura (2000, p.22)”. Miranda (2002, p.56) também expõe a opinião de Hobsbawn $(1995)^{7}$ ao falar sobre a história do século XX, o qual considera que vivemos a "era dos extremos", devido aos paradoxos que se nos apresentam. A começar pelo próprio avanço tecnológico de um lado e o extermínio de culturas e povos (seja pela miséria, seja pela guerra) de outro.

Arocena (2004, p.208) complementa que a tecnologia tem multiplicado e transformado qualitativamente o poder de produzir e destruir, de curar e depredar, de ampliar a cultura dos seres humanos e de gerar riscos para a vida, sendo que esse poder associado aos perigos está distribuído social e regionalmente, de maneira muito desigual. Dessa maneira a ciência e a tecnologia têm feito que o poder se fixe nas mãos de alguns seres humanos.

Vive-se num mundo em que a tecnologia representa o modo de vida da sociedade, na qual a cibernética, automação, engenharia genética, computação eletrônica são alguns dos ícones que da sociedade tecnológica que nos envolve diariamente. Por isso, a necessidade de refletir sobre a natureza da tecnologia, sua necessidade e função social.

\footnotetext{
${ }^{7}$ HOBSBAWN, E. A era dos extremos: o breve século XX. São Paulo: Cia das Letras, 1995.
} 
Para Bazzo, Linsingen e Pereira (2003, p.41), a imagem convencional da tecnologia é que ela sempre teria como resultado produtos industriais de natureza material, manifestada nos artefatos tecnológicos (máquinas), cuja elaboração tenha seguido regras fixas ligadas às leis das ciências físico-químicas, ou seja, a tecnologia numa visão convencional seria a ciência aplicada. Isso implica dizer que a tecnologia é redutível à ciência e que é respaldada pela postura filosófica do positivismo lógico de importante tradição acadêmica, para o qual as teorias científicas são valorativamente neutras, em que, os cientistas não são responsáveis pela aplicação da ciência (tecnologia), mas sim a responsabilidade deveria recair sobre aqueles que fazem uso da tecnologia (ciência aplicada). Essa imagem contribuiu para sustentar a idéia de que se a ciência é neutra, os produtos de sua aplicação também são.

Dizer que a tecnologia é uma ciência aplicada para Luján e Cerezo (2004, p.82), sugere que a aplicação é posterior à aquisição de um conhecimento confiável sobre seus possíveis efeitos, ou seja, a aplicação tecnológica se produz debaixo do amparo do conhecimento teórico. Assim, há poucas possibilidades de se produzirem surpresas desagradáveis, já que o conhecimento científico prévio é a melhor ferramenta para controlar as conseqüências de uma aplicação tecnológica, pois não se trata de um processo cego de ensaio e erro e sim de uma intervenção no mundo, baseado no conhecimento teórico e do método experimental próprio da ciência moderna.

A tecnologia, por muito tempo, foi considerada, ingenuamente, neutra. Todavia, a partir do movimento $\operatorname{ludita}^{8}$ em relação à tecnologia, a maneira ingênua como ela era tratada começa a ser questionada começando-se a perceber que a ciência não é neutra, que apesar de algumas serem utilizadas para o benefício dos seres humanos, também existem outras que são prejudiciais.

Nessa perspectiva, Laranja, Simões e Fontes (1997, p.23) contribuem: "Ciência e tecnologia não são neutras, pois refletem as contradições das sociedades que as engendram, tanto em suas organizações quanto em suas aplicações. Na realidade, são formas de poder e de dominação entre grupos humanos e de controle da natureza".

Sale apud Bazzo, Linsingen e Pereira (2003, p.72) também argumenta que a partir do movimento ludita o custo/benefício do industrialismo começa a ser questionado, pois esse está relacionado fundamentalmente nas bases econômicas de sua utilização não se preocupando com as questões culturais, sociais ou ambientais, ou seja, ocorre uma divisão de custo/benefício injusta e que trata de impor princípios principalmente econômicos destruindo os costumes tradicionais adquiridos até então.

Miranda (2002, p.11) colabora ao afirmar:

\footnotetext{
${ }^{8}$ Segundo Bazzo, Lisingen e Pereira (2003a, p.71), “O movimento ludita operou entre 1811 e 1816 e tratava-se de um movimento que apoiava os trabalhadores que se ressentiam das reduções salariais, da exploração infantil, da supressão das leis e costumes que em uma época tinham protegido os trabalhadores qualificados. O descontentamento levou-os a destruir as máquinas, a maioria da indústria têxtil. Desde então, "o termo 'ludita' passou a significar uma oposição radical à tecnologia".
} 
$\mathrm{Na}$ modernidade (a partir do séc. XVI), devido a fatores históricos, sociais, culturais, econômicos, políticos, a tecnologia sofre e propicia transformações profundas. E muito além de alterar padrões de comportamento, a tecnologia, a partir da modernidade, contribui para alterar a relação do ser humano com o mundo que o cerca, implicando no estabelecimento de uma outra cosmovisão, diferentemente daquela dos gregos ou dos medievais.

Por isso mesmo, a tecnologia moderna não pode ser considerada um mero estudo da técnica, pois quando a ciência, a partir do renascimento, aliou-se à técnica, com o fim de promover a junção entre o saber e o fazer (teoria e prática), nascia aí a tecnologia moderna. Diante desse panorama, pode-se dizer que a tecnologia é um fenômeno social, complexo, que nos conduz a um posicionamento valorativo frente a ela.

Segundo Miranda (2002, p.24), muitos são os autores que apresentam suas avaliações e posições sobre a valoração social da tecnologia. Em sua dissertação de mestrado (2002) no tópico que faz uma análise sobre a dimensão ontológica da tecnologia moderna, essa pesquisadora apresenta três diferentes posicionamentos existentes atualmente na doutrina a respeito da função social da tecnologia, os quais podem ser classificados como visão otimista, visão pessimista e visão moderada da tecnologia.

Entre os que possuem uma visão mais otimista sobre a tecnologia ela cita Schaff (1993), o qual faz sua reflexão sobre a sociedade informática. A visão otimista é própria daqueles que defendem incondicionalmente a tecnologia e que usam como argumentos que a tecnologia é garantia de bem-estar para os seres humanos, desobrigando-os do trabalho pesado, e é considerada como necessidade fundamental para o progresso e o desenvolvimento, e como curso natural do desenvolvimento e do progresso científico.

A visão oposta é a dos pessimistas, que consideram que na origem da tecnologia está a destruição da vida e do planeta e que, se o quadro de desenvolvimento tecnológico permanecer como está hoje, não há sequer possibilidade de reversão do quadro de destruição. Dentre os autores com esse tipo de visão, destaca-se Enguita (1991, p. 231), o qual critica que além da eliminação do trabalho humano, que para os marxistas é inerente ao processo de hominização do homem, a tecnologia é orientada pelo lucro existindo em função da maior produção; por isso, a necessidade de robotização, o que levará a destruição dos homens.

Em relação às duas posições anteriores, considerar a ciência e a tecnologia como remédio para todos os males, cujo fomento seria fundamental na superação do atraso tecnológico dos países subdesenvolvidos, consistiria seguir os mesmos caminhos dos países ricos, o que é inviável. Da mesma maneira, considerar a tecnologia avançada somente como prejudicial é uma generalização que também pode ser perigosa servindo para promover o subdesenvolvimento. Por isso, a necessidade de se buscar uma atitude mais prudente na sua geração e sua utilização. 
A terceira visão citada por Miranda (2002) é a moderada, a qual prega a necessidade de repensar a direção dada à tecnologia hoje, advertindo da necessidade de minimizar os riscos sem, contudo, abdicar dos benefícios que a tecnologia propicia a humanidade. Com essa visão, Miranda (2002, p.25) cita Kneller, que assim se expressou:

\begin{abstract}
O caminho mais sensato é almejar um progresso limitado e manter seus inevitáveis custos em nível mínimo.

Alguma inovação tecnológica é essencial e desejável. Ela tem sido necessária à modernização de todas as sociedades, e habilitará a nossa a sobreviver e melhorar. O desenvolvimento de novas tecnologias deve ser encorajado e o treinamento de tecnólogos imaginativos promovido. [...] A tecnologia pode criar ou destruir, tornar o homem mais humano ou menos. Mas as civilizações, como os indivíduos, devem correr riscos se quiserem progredir. Se exercermos prudência para minimizar os danos da tecnologia e incentivar o máximo seus benefícios, certamente valerá a pena aceitar o risco.
\end{abstract}

Os pensadores que se encontram nesse tipo de visão enfatizam um sistema tecnológico capaz de se adequar a uma sociedade democrática mais humana. Porém, o que temos presenciado é que, com a modernidade, a ciência não tem se constituído num saber livre e desinteressado, teórico e especulativo. Com a modernidade, a ciência e a tecnologia passaram a ter outro significado. Com o advento da sociedade mercantilista, a ciência moderna não surgiu como uma ciência pura e desinteressada, como uma aventura espiritual ou intelectual. Japiassu (1991, p.157) afirma que ela nasceu:

[...] dentro de um contexto histórico, separável de um movimento visando a racionalização da existência. E é todo desenvolvimento da sociedade comercial "industrial" técnica e científica que se inscreve no programa prático da racionalidade burguesa: não se faz comércio empiricamente, pois ele é um negócio de cálculo, deve ser feito racionalmente. Assim a burguesia nascente, que logo se instala no poder, tem necessidade de um sistema de produção permitindo-lhe uma exploração sempre maior e mais eficaz da Natureza. E tal sistema não tarda a fazer apelo a um novo tipo de trabalhador: o cientista. Doravante cabelhe a responsabilidade de detectar as leis gerais da Natureza. Quanto ao trabalho propriamente produtivo [...], é da alçada de engenheiros, que utilizam as descobertas dos cientistas em termos de aplicações particulares.

O progresso técnico não é uma invenção dos tempos modernos, pois já existia o moinho d'água que foi bastante utilizado no século XIII. Pode-se, entretanto, dizer que a ciência moderna tem papel preponderante para o desenvolvimento tecnológico, especialmente nos países denominados "desenvolvidos". Segundo Habermas (1994), ocorreu uma "cientifização da técnica" uma vez que no capitalismo sempre existiu a pressão institucional para aumentar a produtividade do trabalho através da introdução de novas técnicas. Entretanto, as inovações dependiam de invenções esporádicas, que podiam ser introduzidas economicamente ainda com uma característica de crescimento natural.

A partir do séc. XIX isso mudou, na proporção em que o progresso técnico entrou em circuito retroativo com o progresso da ciência moderna. Com a pesquisa industrial em grande 
escala, ciência, técnica e valorização foram inseridas no mesmo sistema. Nesse mesmo tempo, a industrialização estava vinculada a pesquisas encomendadas pelo estado favorecendo primeiramente, o progresso científico e técnico do setor militar, de onde partem as informações para os setores de bens civis. Dessa forma, a ciência e a técnica passam a ser a principal força produtiva.

A tecnologia concede à ciência precisão e controle nos resultados de suas descobertas, facilitando não só a relação do homem com o mundo como possibilitando dominar, controlar e transformar esse mundo. Segundo Miranda (2002, p.48), a teoria crítica dos frankfurtianos considera "que a ciência moderna instrumentalizou a razão e escravizou o homem através do controle lógico-tecnológico criando a tecnocracia, onde toda a vida humana é conduzida e determinada pelos padrões técnicos impostos pela ciência. Tudo se submete às regras da produção tecnológica". Miranda (2002, p.48) continua: "Hoje quem dirige e controla a pesquisa científica é o poder tecnológico, situado fora, inclusive, dos grandes centros de pesquisa, como as universidades. Estas perderam, em grande parte, o senso de ciência como pesquisa livre e com autonomia e se tornaram referência de pesquisas encomendadas por centros de tecnologia, feitas, inclusive, sem que os cientistas jamais saibam de sua finalidade".

Contrariando essa postura entende-se que defensores e questionadores do desenvolvimento tecnológico devem atender, sobretudo, o "poder coletivo" que geram, incluindo-se aí o potencial para a destruição, para realizar as atividades perigosas e para depredar a natureza e, também os benefícios para a saúde humana, inclusive a preservação ou construção de relações que não degradem o meio ambiente. Entretanto, o balanço entre um ou outro tipo de atividade, depende fundamentalmente de como é distribuído o poder gerado pela ciência e pela tecnologia, ou seja, de quem ou de como são manipuladas.

Esses fatores nos evidenciam a necessidade de se refletir as diferentes problemáticas, para isso, é necessário que todos os cidadãos tenham acesso à cultura científica que lhes permitam desenvolver-se em um mundo impregnado pelos avanços científico-tecnológico, que lhes leve a atuar responsavelmente tomando decisões fundamentais e resolvendo problemas cotidianos. Esta cultura científica deve ser assegurada a todos os cidadãos, especialmente àqueles que serão futuros responsáveis pelo desenvolvimento científico-tecnológico.

Dessa forma, surge a preocupação com a educação em todo este processo, especialmente a educação tecnológica que forma pessoas que serão além de usuários geradores de inovações tecnológicas. Propõe-se, então, uma educação com uma abordagem em Ciência, Tecnologia e Sociedade (CTS) como uma das alternativas possíveis visando contribuir para uma compreensão maior sobre a sociedade demandada pelas inovações científico-tecnológicas.

\section{A importância do movimento CTS}


O aparecimento dos estudos CTS no campo acadêmico é reflexo da necessidade de uma compreensão mais completa do contexto social da ciência e da tecnologia. Segundo Cerezo (2002, p.3-4), os estudos sobre ciência, tecnologia e sociedade (CTS), constituem hoje um vigoroso campo de trabalho, no qual se busca entender o fenômeno científico-tecnológico no contexto social, tanto na relação com suas condicionantes sociais, quanto no que se refere às suas conseqüências sociais e ambientais.

A abordagem geral critica a clássica visão essencialista da ciência e da tecnologia que tem orientado entendimentos e ações desde a revolução industrial, e promove o caráter interdisciplinar, abordando-se nela disciplinas como filosofia, história da ciência e da tecnologia, sociologia do conhecimento científico, teoria da educação e economia da mudança tecnológica. Cerezo (2002, p.7) ainda afirma que os estudos CTS apresentam a ciência e a tecnologia não como um processo ou atividade autônoma, que segue uma lógica interna de desenvolvimento em seu funcionamento ótimo, mas como um processo ou produto inerentemente social, em que os elementos não técnicos como: valores morais, convicções religiosas, interesses profissionais, pressões econômicas, entre outros desempenham um papel decisivo em sua gênese e consolidação. Tais elementos não técnicos são necessários na forma de valores ou de interesses contextuais devido à complexidade dos problemas abordados e sua flexibilidade interpretativa.

Nessa linha de argumentação Mitcham, (1996, p.11) contribui declarando que:

\begin{abstract}
Como movimento social, CTS põe em dúvida que o desenvolvimento tecnológico seja sempre benéfico para a sociedade. Como programa acadêmico, por um lado critica a idéia de autonomia sociocultural, questionando se acaso a liberação da tecnociência de toda liberação sociocultural não supõe criar uma sociedade tecnocientífica, isto é, uma sociedade e uma cultura limitada pela ciência e pela tecnologia. Por outro lado, os estudos CTS supõem também um esforço para infundir a esta nova sociedade tecnocientífica um conhecimento mais profundo da ciência e da tecnologia em que se apóia, a fim de que os cidadãos desta nova ordem sejam capazes de ser participantes de decisões que afetam a sua vida.
\end{abstract}

O poder associado ao conhecimento científico e tecnológico, assim como os riscos que o mesmo gera, constitui um desafio maior para as capacidades de decisão democrática. Segundo Arocena (2004, p.222) este pode ser um estímulo significativo para que a formação cidadã, uma formação que oportunize participar das grandes opções a que todos têm direito, se converta em uma meta das políticas públicas. Nesse sentido, o enfoque CTS pode contribuir para a expressão das capacidades coletivas tanto para fazer como para resolver questões científicas e tecnológicas, sobretudo se o que se prioriza é a comunicação e a cooperação entre perspectivas distintas. 
Nesse contexto, Cerezo (2002, p.7) apresenta as idéias de Sanmartín (1990) e Winner (1986), os quais expressam a necessidade de fazer reflexões sobre o atual desenvolvimento científico-tecnológico e também de se propor linhas de ação para problemas como:

a) equidade na distribuição dos custos ambientais da inovação tecnológica, como por exemplo: experiências com organismos geneticamente modificados);

b) o uso impróprio de descobertas científicas como diferenças sexuais em tipos de conduta inteligente;

c) as implicações éticas de algumas tecnologias, tais como: uso comercial da informação genética, barrigas de aluguel;

d) a aceitação dos riscos de outras tecnologias, como por exemplo: energia nuclear, fertilizantes químicos;

e) a modificação na natureza do exercício do poder devido a atual institucionalização da assessoria especializada - problema da tecnocracia.

Portanto, os estudos CTS constituem a resposta por parte da comunidade acadêmica à crescente insatisfação com a concepção tradicional de ciência-tecnologia, aos problemas políticos e econômicos relacionados com o desenvolvimento científico-tecnológico e aos movimentos sociais de protesto que surgiram nos anos de 1960 e 1970. Compõem um campo de trabalho interdisciplinar orientando à compreensão do fenômeno científico-tecnológico em sua relação com o contexto social, tanto em relação aos fatores econômicos, políticos e culturais que exercem influência sobre o desenvolvimento científico-tecnológico, como no que se refere às conseqüências que essa mudança traz para a sociedade e para o meio ambiente. Para Garcia et al (1996) a partir da abordagem CTS, a ciência é considerada uma atividade humana complexa, com um grande potencial explicativo e instrumental, mas que tem lugar em contextos sócio-políticos determinados.

Os estudos sociais da ciência e da tecnologia $(\mathrm{CTS})^{9}$ tomaram importante rumo a partir de meados de 1960 e início de 1970, como resposta ao crescimento do sentimento generalizado de que o desenvolvimento científico e tecnológico não possuía uma relação linear com o bem-estar social, como se tinha feito crer desde o século XIX. Mitcham (1996, p.9) Cutcliffe e Mitcham (1994, p. 190) alegam que isso se deu porque se começou a tomar consciência dos acontecimentos sociais e ambientais associados às atividades científico-tecnológicas. Os estudos CTS iniciaram tanto no

\footnotetext{
${ }^{9}$ Nos Estados Unidos, teve a criação da agência de Proteção do Meio Ambiente (1970), ou a Oficina do Congresso para Assessoramento Tecnológico; na Europa o estabeleceram-se as "tendas de ciência" da Noruega e a formação dos partidos "verdes" (especialmente na Alemanha). Em um plano internacional, a reunião da Conferência sobre o Entorno Humano das Nações Unidas em Estocolmo e a publicação do Informe do Clube de Roma sobre os limites do crescimento, ambos em 1962, intensificou mais ainda a ação pública e as implicações intelectuais nos temas CTS. Prolongações nas décadas seguintes se pode contemplar a com a destruição da capa de ozônio da atmosfera pelos agentes CFC (confirmada em 1985 e que conduziu a sua supressão no Protocolo de Montreal), a aparição da retórica de desenvolvimento sustentado (Comissão Mundial sobre Meio Ambiente e Desenvolvimento, 1987), e a Carta da Terra no Rio de Janeiro, 1992).
} 
Norte da América quanto na Europa surgindo como uma reconsideração crítica do papel da ciência e da tecnologia na sociedade, embora com orientações distintas.

Cutcliffe e Mitcham (1994, p.190), acrescentam que intelectuais de diferentes perspectivas, incluindo-se aí personalidades como Lewis Mumford e Jacques Ellul ${ }^{10}$, sugeriram que havia externalidades negativas associadas aos benefícios que durante muito tempo se supôs eram o legado principal da ciência e da tecnologia.

As condições para uma nova forma de ver as interações entre ciência, tecnologia e sociedade se estabeleceram num clima de tensão gerado pela guerra do Vietnã, pela guerra fria, pela difusão midiática de catástrofes ambientais e dos horrores provocados pelo aparato tecnológico de destruição posto a serviço da morte, dos movimentos ambientalistas, da contracultura que se iniciavam, e também da crítica acadêmica à tradição positivista da filosofia e da sociologia da ciência, que se estabelecem.

Todos esses fatores acarretaram um interesse crescente sobre as complexidades da ciência e da tecnologia da sociedade contemporânea com a intenção de gerar uma aproximação mais interdisciplinar para entender tanto os efeitos positivos como negativos do desenvolvimento científico tecnológico. Cutcliffe (1996, p.52) complementa que, semelhante a esta resposta política, também ocorreram mudanças similares em alguns campos acadêmicos, evoluindo em grande medida a partir de acadêmicos como Lewis Mumford, Thomas Kuhn, John Ziman e J. D. Bernal, historiadores, sociólogos e filósofos da ciência e da tecnologia que desviaram de subdisciplinas de caráter internalista para fazer interpretações mais externalistas ou conceituais. Essa mudança expressava as mesmas forças sociais e intelectuais que conduziram diretamente a aproximação interdisciplinar dos estudos CTS.

A abordagem CTS, dependendo de como se entenda a contextualização social da ciência e da tecnologia, pode identificar duas grandes tradições com diferentes interesses e pontos de partida: a de origem européia e a de origem americana, mas que não serão abordadas por não ser o foco desse artigo.

\section{Considerações Finais}

Apesar de todos os benefícios que a ciência moderna e a tecnologia têm proporcionado aos seres humanos, vem crescendo o discurso crítico sobre o risco que elas podem causar no cenário da sociedade moderna, embora seja um assunto controvertido já que trata do risco e não do progresso.

Numa sociedade em que o desenvolvimento científico-tecnológico tornou-se hegemônico é fundamental refletir sobre a tecnologia numa outra perspectiva. O que se vê é que o progresso

\footnotetext{
${ }^{10}$ Lewwis Mumford. The Myth of the Machine, 2 vols (nova York, Harcout Brace Javanovich, 1967-1970); Jacques Ellul, The Technological Society, traduzido por John Wilkinson (Nova York, Alfred A. Knopf, 1964).
} 
tecnológico não tem atendido às necessidades básicas da população e sim tem servido para a promoção de interesses de poucos como estratégia do sistema capitalista. Entende-se que as prioridades que os governantes têm dado à tecnologia precisa ser revista na busca da promoção humana, visando melhorar a qualidade de vida da população, fato que não ocorre efetivamente.

Poder-se dizer então que o crescimento da importância do conhecimento e a aceleração na produção de inovações faz com que as assimetrias e desigualdades sociais estejam propensas a agravar-se na mesma velocidade, ficando mais difícil superá-las e exigindo cada vez mais esforços na tentativa de reverter-lhas.

Nos últimos anos, a pesquisa básica tem concentrado seus esforços em campos muito distantes das necessidades cotidianas da sociedade. A ciência e a tecnologia visam atender às necessidades das classes dominantes e dos governos que representam empresas poderosas, de modo que somente uma pequena parcela da população pode usufruir de seus serviços e inovações, acentuando a desigualdade social, ao mesmo tempo em que garante o lucro de um seleto grupo de empresas.

Se o que se visa é o bem-estar geral e não o lucro máximo, deve-se mudar o critério para o desenvolvimento científico-tecnológico e, conseqüentemente o econômico. É necessário haver uma modificação radical do lugar da ciência na sociedade, de forma a abrir as portas do mundo científico e tecnológico a toda a população e não somente a uma "elite", vinda das classes dirigentes ou por eles selecionada.

O desenvolvimento científico-tecnológico deve ser encorajado a florescer e a progredir levando em consideração o bem-estar do povo e não somente o econômico como acontece nos dias de hoje. Um desenvolvimento científico-tecnológico com responsabilidade social deve se voltar para as tarefas práticas, não pode ser dirigido de acordo com os velhos sistemas econômicos, políticos e moral. Implica ter um nível de responsabilidade individual e coletiva muito mais acentuado que o dos tempos anteriores. Por isso, a necessidade de se proporcionar a toda população uma educação científica e tecnológica, pois a ausência de conhecimentos induz à ausência de responsabilidade.

Considerando a problemática do desenvolvimento científico e tecnológico para que ela seja menos excludente, é necessário que se leve em conta os reais problemas da população, os riscos técnico-produtivos e a mudança social. Por isso, faz-se necessário ter uma visão interativa e contextualizada das relações entre ciência, tecnologia, e sociedade e, muito especialmente, nas políticas públicas mais adequadas para gestionar às oportunidades e perigos que envolvem uma mudança tecnológica, ou seja, a questão não é tanto se a ciência é boa ou não, mas sim se pode melhorar e como dentro de um contexto sócio-ambiental harmônico? 
Em vista disso, nos anos 1960 e 1970 começou a se manifestar, nos países desenvolvidos, começou a se manifestar o movimento CTS (Ciência, Tecnologia e Sociedade) através da comunidade acadêmica que, insatisfeita com a concepção tradicional da ciência e da tecnologia e preocupada com os problemas políticos e econômicos decorrentes do desenvolvimento científicotecnológico e com os movimentos sociais de protestos, começou a buscar análise e estudos na área de CTS; os quais são muito recentes no Brasil. Tal movimento nasceu com caráter crítico, tanto em relação à visão essencialista da ciência e da tecnologia, bem como com a visão interdisciplinar entre as diversas áreas do conhecimento, incentivando o questionar das certezas absolutas sobre a ciência, desvelando a sua não neutralidade e tomando decisões mais coerentes em relação aos problemas nos quais os conhecimentos científicos estejam presentes.

Por isso, destaca-se a importância da sua inserção, mais do que nunca, também no ambiente educacional de forma a propagar uma educação mais eficaz a fim de modificar com rapidez um sistema de desenvolvimento científico-tecnológico que acumula, a cada dia mais riqueza para uns poucos e miséria para a grande maioria. É necessária uma mudança de atitude, de comportamento para construir o mundo que desejamos e, para isso, é indispensável proporcionar a todos uma educação contextualizada com a dimensão social da ciência e da tecnologia.

Nesse sentido, a educação CTS é uma inovação que tem a intenção de promover uma ampla alfabetização científico-tecnológica $(\mathrm{ACT})^{11}$ numa perspectiva ampliada (o modelo interacionista) de maneira que os cidadãos tenham condições de tomar decisões responsáveis, no que se refere às questões tecnológicas predominantes na sociedade contemporânea, como por exemplo: a contaminação ambiental, o esgotamento dos recursos naturais, a ameaça da guerra nuclear, a liberação de organismos geneticamente manipulados, a deterioração da qualidade de trabalho tendo como causa a automatização, entre outros.

\footnotetext{
Abstract

This paper shows ups the transformation of the human being relation with the world caused by the scientific advance. In this way, the purpose of this paper is to reflect how the science and the technology have been installed in the world, what are the conceptions and ideologies that are behind of the scientific development. It begins talking how traditionally the science is seen. In the sequence, it comments about the origin and the dissemination of the technology, how it suffers and causes deeply transformations concerning political, social, economic and philosophical aspects in the history of XVII century forward. Finally, it defends the necessity of thinking about the scientific and technological development in a social perspective, with transformations that the science and technology have been suffering after the Second World War I, and the importance of the CTS

11 Quando falo em alfabetização científico-tecnológica (ACT), defendo uma ACT numa perspectiva ampliada, o modelo interacionista. Nesse modelo "concebe-se a ACT como uma busca da compreensão das interações entre ciência, tecnologia e sociedade, ou seja, o ensino de conceitos associado ao desvelamento de mitos vinculados a ciência-tecnologia, bem como a discussão sobre dinâmica de produção e apropriação do conhecimento científico-tecnológico. Em outras palavras, ACT deve, também propiciar a reflexão sobre quem define a agenda de investigação, no campo científico-tecnológico, e em função de que objetivos" (AULER, 2002, p. 19-20)
} 
movement as a booster of critical and reflective queries concerning the scientific, technological and social context.

Key words: Scientific and Technological Development; Science, Technology and Society (STS); Technological; Technology; Science.

\section{Referências}

AROCENA, R. Riesgo, cambio técnico y democracia en el subdesarrollo. In: LUJÁN, José L. y ECHEVERRÍA, Javier. Gobernar los Riesgos: ciencia y valores en la sociedad del riesgo. Madrid: Biblioteca Nueva - OEI, 2004, pp. 207-223.

BASTOS, J. A. S. L. A. de (Org.). Tecnologia e interação. Curitiba: CEFET-PR, 1998, p.13.

BAZZO, W. A.. Ciência, tecnologia e sociedade: e o contexto da educação tecnológica. Florianópolis: Ed. da UFSC, 1998.

BAZZO, W. A.; LINSINGEN, I. V.; PEREIRA, L. T. V. Inovação tecnológica ou inovação social? In: Congresso Brasileiro de Ensino de Engenharia, XXXI, 2003, Rio de Janeiro-RJ. Anais do XXXI Congresso Brasileiro de Ensino de Engenharia. Rio de Janeiro-RJ. Setembro de 2003. CD-ROM, 9p.

BERNAL, J. D. Ciência na História. v. VII. Lisboa: Livros Horizonte, 1969.

CEREZO, José Antonio Lopez. Ciência, Tecnologia e Sociedade: o estado da arte na Europa e nos Estados Unidos. In: SANTOS, Lucy Woellner dos; ICHIKAWA, Elisa Y.; SENDIN, Paulo V. e CARGANO, Doralice de F. (orgs). CIÊNCIA, TECNOLOGIA E SOCIEDADE: o desafio da interação. Londrina: IAPAR, 2002, pp. 3-39.

CAMPOS, R. R. O paradigma tecnológico da indústria de carnes. IN: SBRAGIA, R; MARCOVITCH, J. \& VASCONCELOS, E. (Orgs.). In: XIX SIMPÓSIO DA GESTÃO DA INOVAÇÃO TECNOLÓGICA. São Paulo, USP. Anais XIX Simpósio Da Gestão Da Inovação Tecnológica. São Paulo, 1996, pp. 282-299.

CARVALHO, M. G.. Tecnologia, Desenvolvimento Social e Educação Tecnológica. Revista Educação \& Tecnologia. Curitib : Centro Federal de Educação Tecnológica do Paraná, julho de 1997, semestral, p.70-87.

CUTCLIFFE, S. H. E MITCHAM, C. Una descrición de los programas y la educacion CTS Universitária en los Estados Unidos. In: SANMARTÍN, J. E HRONZSKY (eds). Superando fronteras: estudos europeos de Ciencia-TecnologíaSociedad y educación de tecnologías.

CUTCLIFFE, S. H. Programas universitarios y no universitarios en los Estados Unidos y Europa: observaciones desde y sobre el terreno. In: ALONSO, Andoni; AYESTARÁN, Ignacio e URSÚA, Nicanor (coord.). Para Comprender Ciencia, Tecnología y Sociedad. Espanha: Editorial Verbo Divino, 1996, pp. 49-61.

ECHEVERRÍA, J. Tecnologias, espacios de interacion y valores. In: CEREZO, J. A. L.; LUJÁN, J. L.; PALÁCIOS, E. M. G. (eds). Filosofia de la tecnologia. Madrid: Organização dos Estados Iberoamericanos para la Educación, la Ciência y la Cultura (OEI), 2001, pp. 15-29.

ENGUITA, M. F. Tecnologia e sociedade; a ideologia da racionalidade técnica, a organização do trabalho e a educação. In SILVA, Thomaz T. da. Trabalho, educação e prática social; por uma teoria da formação humana. Porto Alegre: Artes Médicas, 1991.

GARCIA, Marta I. González; CEREZO, José A López. LOPEZ, José L. Ciencia, Tecnología y Sociedad. Madrid: Tecnos, 1996.

HABERMAS, J. Técnica e ciência como ideologia. Lisboa : Edições 70, 1994, pp330 e 331.

JAPIASSU, H. O mito da neutralidade científica. Rio de Janeiro : Imago Editora Ltda, 2a ed., 1981. As paixões da ciência: estudos de história das ciências. São Paulo : Letras \& Letras, 2a ed.,1991.

KUHN, T. A estrutura das revoluções científicas. São Paulo: Perspectiva, 1989. 
LARANJA, M.; SIMÕES, V. C.; \& FONTES, M. Inovação tecnológica-experiências das empresas portuguesas. Lisboa, Texto, 1997.

LUJÁN, J. L. y CEREZO, J. A. L. De la promoción a la regulación. El conhecimento científico en las políticas públicas de Ciencia e Tecnología. In: LUJÁN, José L. y ECHEVERRÍA, Javier. Gobernar los Riesgos: ciencia y valores en la sociedad del riesgo. Madrid: Biblioteca Nueva - OEI, 2004.

MENÉNDEZ, P. G. Las estrategias de resolución de problemas y el estúdio científico del riesgo: el caso de los alimentos transgênicos. In: LUJÁN, José L. y ECHEVERRÍA, Javier. Gobernar los Riesgos: ciencia y valores en la sociedad del riesgo. Madrid : Biblioteca Nueva - OEI, 2004, pp. 263-287.

MITCHAM, Carl. Los estúdios de ciência, tecnologia y sociedad. Uma introdución conceptual. In: ALONSO, Andoni; AYESTARÁN, Ignacio e URSÚA, Nicanor (coord.). Para Comprender Ciencia, Tecnología y Sociedad. Espanha: Editorial Verbo Divino, 1996, pp.09-12.

MIRANDA, A. L. Da natureza da tecnologia: uma análise filosófica sobre as dimensões ontológica, epistemológica e axiológica da tecnologia moderna. 2002 pp. 161 (Dissertação de mestrado). Programa de Pós-Graduação em Tecnologia do Centro Federal de Educação Tecnológica do Paraná (CEFET-PR)

MORIN, E. Ciência com consciência. Rio de Janeiro: Bertrand Brasil, 1996.

SANTOS, B. S de. Crítica da razão indolente contra o desperdício da experiência. São Paulo: Cortez, 2000 , p.22 e SS.

\section{Dados completos do primeiro autor:}

Nome completo: Rosemari Monteiro Castilho Foggiatto Silveira

Filiação Institucional: Universidade Tecnológica Federal do Paraná

Endereço: Av. Anita Garibaldi 1771, casa 12. Vila Órfãs

Condomínio Parque dos Príncipes

Ponta Grossa - PR, Brasil

CEP: 84015-050

Fone: 224-58-55 / 99210868

e-mail: rosemari@.pg.cefetpr.br

Recebido para publicação em: 18/12/2005

Aceito para publicação em: 19/04/2006 